\title{
COVID-19: A Significant Revival Approach - Concurrent Case Study in India
}

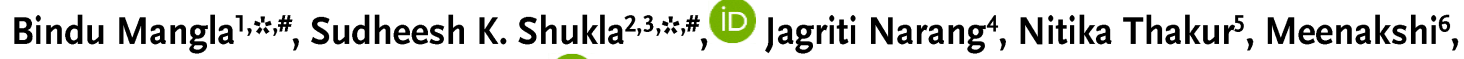 \\ Chaudhery Mustansar Hussain ${ }^{7, *}$, (iD) \\ ${ }^{1}$ Department of Chemsitry, J.C. Bose University of Science and Technology YMCA, Faridabad, India \\ ${ }^{2}$ School of Environmental Science and Engineering, Shandong University, Jimo, Qingdao 266237, P.R. China \\ ${ }^{3}$ VBRI, 7/16 Kalkaji Extn., New Delhi 110 019, India \\ ${ }^{4}$ Department of Biotechnology, Jamia Hamdard University, New Delhi 110062, India \\ ${ }^{5}$ Department of Biotechnology, Shoolini University of Biotechnology and Management Sciences, Bajhol, Solan, \\ Himachal Pradesh, India \\ ${ }^{6}$ The Swiss Institute for Dryland Environmental and Energy Research, The Jacob Blaustein Institutes for Desert Research, \\ Ben-Gurion University of the Negev, Midreshet Ben-Gurion 8499000, Israel \\ ${ }^{7}$ Department of Chemistry and Environmental Science, New Jersey Institute of Technology, Newark, New Jersey 07102, USA
}

*Corresponding address: E-mail: bindumangla@gmail.com (B.M.); sudheeshkshukla@gmail.com (S.K.S.);

chaudhery.m.hussain@njit.edu (C.M.H.)

\#Contributed equally

DOI: $10.5185 /$ amlett.2021.021598

In current pandemic, as there is no approved specific antiviral agent for coronavirus disease (COVID-19) available till to date; Indian Ayurveda has emerged out as effective tool to control the prevailing pandemic at initial stage mainly by gearing up the immune system. Convalescent plasma therapy (CPT) has shown a glimpse of hope and some case study supported the hypothesis that CPT could be a prospective treatment option. The current study reported first time on a real time case study in India along with the outcome that CPT could be potentially improved the treatment of severe COVID-19. The CPT results presented here have shown that clinical symptoms were significantly improved along with increase of oxyhemoglobin saturation, also increased lymphocytes count whereas decreased C-reactive proteins within 3 days without any severe adverse side effect.

\section{Introduction}

Worldwide data reveal the low mortality rate and high recovery rate in India besides dense population, poor literacy rate, low per capita income and other anthropological and demographic challenges as compared to other developed nations. India is handling the pandemic very smartly and managing a relatively low mortality rate of 1.47 , (the lowest among most affected countries) till now (Table 1). It is a matter of worth pondering that how such a big country is having high recovery. There can be many possible views about it but one very common and accepted in mass is Ayurveda, which is a part of life there. Number of Indian herbs have medicinal value and do wonders in prophylactic and therapeutic activities [1].

Table 1. Worldwide most COVID-19 effected countries*.

\begin{tabular}{lrrrrr}
\hline Country & \multicolumn{1}{c}{$\begin{array}{l}\text { Total } \\
\text { cases }\end{array}$} & Deceases & Recovered $\begin{array}{l}\text { Mortality } \\
\text { rate }\end{array}$ & $\begin{array}{l}\text { Recovery } \\
\text { rate }\end{array}$ \\
\hline Worldwide & 56623643 & 1355963 & 40108847 & 2.39 & 70.83 \\
USA & 11413788 & 248571 & 7316323 & 2.18 & 64.10 \\
India & 9004365 & 132162 & 8478124 & 1.47 & 94.16 \\
Brazil & 5945849 & 167455 & 5422102 & 2.82 & 91.19 \\
France & 2109170 & 48265 & 149521 & 2.29 & 7.09 \\
\hline
\end{tabular}

\begin{tabular}{lrrrll}
\hline Russia & 2039926 & 35311 & 1551414 & 1.73 & 76.05 \\
Spain & 1541574 & 42291 & N/A & 2.74 & N/A \\
UK & 1453260 & 53775 & N/A & 3.70 & N/A \\
Italy & 1345767 & 48569 & 520022 & 3.61 & 38.64 \\
Argentina & 1339337 & 36347 & 1177819 & 2.71 & 87.94 \\
Colombia & 1218003 & 34563 & 1138581 & 2.84 & 93.48 \\
Mexico & 1015071 & 99528 & 770728 & 9.81 & 75.93 \\
Peru & 941951 & 35402 & 873970 & 3.76 & 92.78 \\
\hline
\end{tabular}

*Data source; https://covid19.who.int/table, accessed on 21.11.2020 at 12.30 IST

A very famous Indian herb Tinospora cordifolia commonly known as Giloy is used in Indian medication system since time immemorial against the disease of heart, kidney, liver, blood sugar, skin and other common disease along with its immunity boosting action [2-4]. A very common Indian herb Ashwagandha (Withania somnifera) has been used for decades for immunity lift up and its inhibitory action against many viruses [5-7]. Honeybee propolis is also widely used against a variety of virus infectious disease [8-12]. Recently V. Kumar et. al., (2020) have revealed the effective action of these herbs against currently running pandemic by SARS-CoV-2 with the help of a detailed mechanism of molecular docking and molecular dynamic simulations [13]. Many more 


\section{Advanced Materials Letters www.vbripress.com/aml}

Indian Ayurvedic herbs are known with antiinflammatory, anti-bacterial action and can work for anxiety, arthritis, blood sugar level etc. These have become a way of life style in India and may be acknowledged to gear-up the immunity of people. Presently during the pandemic of corona virus the Ayurvedic medicines/herbs are taking care at prophylactic and initial stage of infection and leading to high recovery rate [14].

However, at advance stage of infection other symptomatic medicines are used, since non-availability of a particular vaccine make the situation more cumbersome. Convalescent plasma therapy looks promising at this stage of time to handle severe cases. A schematic presentation of Indian approach to tackling the COVID cases is presented in Fig. 1.
CPT is a well-established technique and showed great importance during the outbreak of some serious viral outbreak like measles, mumps, influenza and poliomyelitis during early years of previous century [15-19]. Generally, immune system in humans cultivates antibodies and protein against the attack of any virus or bacteria that bind to these foreign elements and encumber the resulting infection. This trend in development of antibodies makes one's active immune system. Moreover, this active immunity lasts long for several types of viruses and bacteria, but sometimes infectious activity overtake the immune system. In such cases readily available antibodies are infused in the body of infected person to fight against the virus immediately.

CPT is a kind of passive immunity. This therapy targets at transfusing antibodies from a recovered person
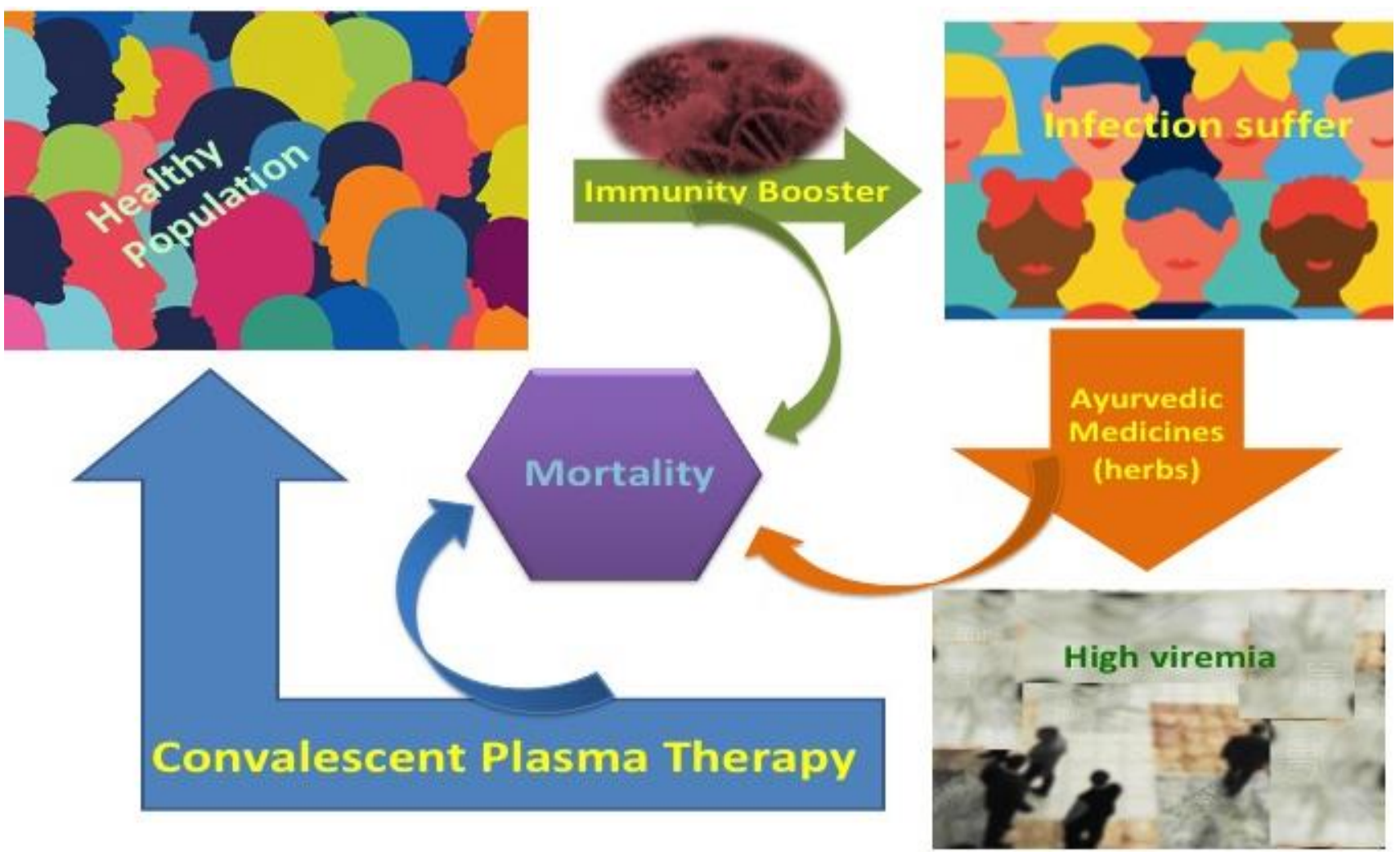

Fig.1. Indian combat approach for the management of COVID-19 in current pandemic scenario.

Time is the quintessence to establish procedures for exploiting convalescent plasma in response to the current pandemic. As convalescent plasma therapy (CPT) has shown a glimpse of hope to current pandemic of coronavirus disease (COVID-19). We have the privilege to first time report results of real time usage of this therapy to COVID-19 patients, which we believe will be very useful in establishment of convalescent plasma as a therapeutic option for COVID-19. Additionally, most of the available reports are on case results from Chinese territory or on theoretical scale, this will be the first report from outside this sphere. to an infected patient. A recently recovered person had developed antibodies as a regular immune response to novel corona virus. In contemporary history, this technique has successfully employed to fight against the pandemic of SARS, MERS and H1N1 influenza 2009 [20-22]. A modern study reported the usage of convalescent sera in China for the patients of COVID-19 [23]. The therapy is claimed to be more effective in prophylactic mode. CP therapy can be used as preventive measure during early stages of infection and hence considered as analogous to passive immunization. 


\section{Advanced Materials Letters www.vbripress.com/aml}

Neutralizing antibody titer is one important criterion in $\mathrm{CP}$ therapy. Donors with high titre value and fit on other clinical considerations can be admitted for CP treatment. Cao et. al., 2007 [24], showed the decreasing levels of neutralizing antibodies to SARS-CoV and MERS-CoV within a couple of months. The studies suggest that donors should be admissible as soon as possible after complete recovery. Some meta-analysis discovered the reduced mortality rate especially when $\mathrm{CP}$ treatment was carried out early after the inception of symptoms.

\section{Discussion}

In one study Convalescent Plasma (CP) Treatment claimed to reduce the mortality rate during $\mathrm{H} 1 \mathrm{~N} 1$ Influenza A 2009 virus pandemic [25]. The study is based on a group of 20 patients who received Convalescent Plasma Treatment in Hong Kong under controlled parameters of their age, weight, allergies etc. The Convalescent Plasma donor had recovered from the same infection for almost two weeks back and qualified for other donor marks like Hepatitis B, Hepatitis C, and HIV etc. Mortality rate was found to drop in-group of patients who were given $\mathrm{CP}$ Treatment significantly as compared to those who denied for such treatment $(20.0 \%$ vs $54.8 \%$ respectively). However, its effectiveness needs more exploration at all stages of infection. The methodology needs broader study to reach to a conclusive idea. Duan et. al., (2020) has discussed their study of CP transfusion in a group of 10 severe COVID-19 patients, where they have been provided with a dose of $200 \mathrm{ml}$ convalescent plasma collected from donors with neutralizing antibody titer value above 1:640, which represent their contemporary retrieval [26]. The therapy claimed a significant improvement to all patients. Most of the clinical parameters upgraded in 3-7 days. Moreover, lung lesions were found to absorb to different extent within 7 days even without any critical adverse consequence. 7 out of those 10 patients were reported negative in their swab test after the treatment. This study comes out with encouraging results of $\mathrm{CP}$ therapy but simultaneously support the further studies on a larger group of patients with varying degree of infections. In another study by Cheng et. al., 2005 [27], eighty of the SARS patients in 2003 in Hong Kong, were administered with convalescent plasma. The study comes out with encouraging results of early discharge and reduction in viremia. Timely infusion (before day 14) gave better results with lower mortality rate without any immediate adverse effects.

\section{Plasma therapy and COVID-19 in India}

COVID-19 statistics in India are relatively at better stage as compared to other contemporary countries until now. But a large population and its demographic distribution are still making it a vulnerable to this pandemic.

CP therapy as a potential preventive measure as well as treatment for COVID-19 is under progress, although some limited trials have been conducted in China, which eventually comes out with results of betterment. In India also the treatment is under trial with a dose of $200 \mathrm{ml}$ of CP.

1. Recently 49 years old man in serious condition of ventilator support, at one of the hospital in New Delhi has been given $\mathrm{CP}$ treatment against the current outbreak of COVID-19. Man start showing a gradual recovery after the treatment without any antagonistic effects and even ventilator support was not required any more. Man was tested RT-PCR test positive on $4^{\text {th }}$ April and admitted on the same day with moderate symptoms. After gradual deteriorating condition and pneumonia development he was taken to ventilator in next 4 days. CP was collected by apheresis from donor who recovered three weeks back and transfused to the patient after 10 days of the onset of symptoms (14 ${ }^{\text {th }}$ April). This lead to a progressive improvement and only after 4 days of CP infusion he was taken off the ventilator support and test negative for novel corona virus.

2. In another trial a group of four persons on $8^{\text {th }}$ April with common symptoms of COVID-19 and pneumonia were admitted to Lok Nayak Jai Praksh Hospital hospital, New Delhi. On $14^{\text {th }}$ of April they were given CP treatment. A regular check on symptoms and clinical parameters were made and found positive improvements in their condition. At day 4 after $\mathrm{CP}$ treatment all were taken out from the intensive care unit of the hospital.

3. Four critically ill patients; a 26 year aged woman and 23, 40 and 55 year aged three males; were chosen for clinical trial of CP treatment on the basis of their degrading condition even after best possible medication at Sri Aurobindo Institute of Medical Sciences (SAIMS) hospital, in Indore India. Patients were suffering from Acute Respiratory Distress Syndrome (ARDS), lung infection along with SARS Cov-2 positive test and surviving with external oxygen support. The therapy were done on April 26, 2020 and within 3 days of the therapy, external oxygen support was withdrawn. They respond negative to RT-PCR test. X-ray and CT scan results confirmed the implausible improvements over lung infection. After two weeks all four patients were discharged successfully. Inspired from such kind of results SAIMS has decided to go further for a bigger trial on 20 patients with variations in their age, conditions, clinical history etc. Although CP treatment during this trial presented a very cheerful results but it does not assure a 100\% efficacy in all the cases.

4. Two elderly, aged 63 and 54 years; COVID-19 patients with moderate symptoms of SARS Cov-2, like low oxygen saturation level, elevated levels of d-dimers, breathlessness and medical history of hypertension, diabetes and bronchitis were given $\mathrm{CP}$ 


\section{Advanced Materials Letters www.vbripress.com/aml}

therapy on May 4, 2020 at SMS hospital Jaipur. Within two days of $\mathrm{CP}$ infusion the symptoms amended extraordinarily.

5. On a similar line one COVID-19 patient at Sasoon hospital, Pune went through CP infusion on 10 and 11 May 2020, successfully and recovered with no contrary effects. One more critically ill patient is now in good health in Hyderabad using the same medical technique.

6. CP therapy is not only known to give improved positive outcomes but sometimes bring displeasure also. A critically ill COVID-19 patient aged 60 year, male, died in Karnataka after the said treatment. However, this should not be taken as a failure since the treatment is not working in isolation.

There are many more such case studies where CP therapy has been proven to be a blessing for patients including health minister of Delhi government, India. Different persons respond differently to the same treatment because of their demographic region, physiological parameters and previous clinical history. On the basis of results of such trials Indian Council of Medical Research (ICMR) had invited trials from all across the country and entered in phase II of CP therapy trials on May 4, 2020, to assess a broader aspect of research in this probable diagnostic avenue of current pandemic. Now establishment of plasma bank has started and taking fuel in India to make it available for people in need on time. The success rate of this therapy is more than $90 \%$ and that's why medical professional relying more on it without waiting for any miracle.

On a very interesting note, one of the Asia's largest slums Dharavi, located in Mumbai, Maharashtra with a surprising population density of 277,136 per sq kilometer, which was a hot spot of COVID-19 by April 2020, but controlled the spread drastically and presented a model to the world. Now plasma-screening camps were organized at Dharavi during since July 2020 where the probable donors undergo physical medical examination regarding their clinical history and respective plasma is screened for infectious disease like HIV, Hepatitis and others. $\mathrm{Hb}$ count, diabetes, cancer, hypertension and comorbidities are some other criteria to be checked for a donor to be eligible donor so that to rule out any aspect of deleterious impact of $\mathrm{CP}$ therapy which ultimately contribute to low mortality of the population. Till now the therapy has not been established as an approved treatment for COVID-19, in fact it is still at experimental stage and need to be explored on a larger sample size with defined conditions.

\section{Conclusion}

All the patients were examined for $\mathrm{CP}$ treatment and mostly responded in a positive manner and results encouraged the teams to go ahead with the idea. Inspired from these trials at New Delhi and other states of India research fraternity is pondering to analyze this treatment on a larger scale so as to use it as a tool against SARSCoV-2. CP Therapy cannot be awarded 100\% credit for the recovery of COVID-19 patients since other medical factors keep working along with it, but it can be said to accelerate the recovery. Overall, there is a need to monitor all those activities, which are employed at global scale to liberate humans from this epidemic as soon as possible.

\section{Keywords}

COVID-19 management, Convalescent plasma therapy, clinical symptoms, severe disease, treatment; clinical symptoms, pandemic health combat.

\section{References}

1. www.ayush.gov.in, Accessed on 20 November 2020.

2. Singh, S.S.; Pandey, S.C.; Srivastava, S.; Gupta, V.S.; Patro, B.; Ghosh, A.C.; Ind. J. Pharma., 2003, 35, 83.

3. Sinha, K.; Mishra, N.P.; Singh, J.; Khanuja, S.P.S.; Ind. J. Trad. Know., 2004, 3, 257.

4. Shah, S.; Ghosh, S.; Ancs. Life Sci., 2012, 31, 151.

5. Munagala, R.; Kausar, H.; Munjal, C.; Gupta, R.C.; Carcinogenesis, 2011, 32, 1697.

6. Cai, Z.; Zhang, G.; Tang, B.; Liu, Y.; Fu, X.; Zhang, X.; Cell Biochem. Biophys., 2015, 72, 727.

7. Latheef, S.K.; Dhama, K.; Samad, H.A.; Wani, M.Y.; Kumar, M.A.; Palanivelu, M.; Malik, Y.S.; Singh, S.D.; Singh. R.; VirusDisease, 2017, 28, 115.

8. Amoros, M.; Lurton, E.; Boustie, J.; Girre, L.; Sauvager, F.; Cormier, M.; J. Nat. Prod., 1994, 57, 644.

9. Lyu, S.Y.; Rhim, J.Y.; Park, W.B.; Arch. Pharm. Res., 2005, 28, 1293.

10. Zandi, K.; Teoh, B.T.; Sam, S.S.; Wong, P.F.; Mustafa, M.R.; AbuBakar, S.; Virol. J., 2011, 8, 560.

11. Pasupuleti, V.R.; Sammugam, L.; Ramesh, N.; Gan, S.H.; Oxid. Med. Cell. Longev., 2017, 2017, 1259510.

12. Kwon, M.J.; Shin, H.M.; Perumalsamy, H.; Wang, X.; Ahn, Y.J.; J. Apic. Res., 2019, 59, 413.

13. Kumar, V.; Dhanjal, J. K.; Kaul, S.C.; Wadhwa, R.; Sundar, D.; J. Biomol. Struct. Dyn., 2020, 10.1080/07391102.2020.1772108.

14. Kumar, V.; Dhanjal, J.K.; Bhargava, P.; Kaul, A.; Wang, J.; Zhang, H.; Kaul, S.C.; Wadhwa, R.; Sundar, D.; J. Biomol. Struct. Dyn., 2020, 10.1080/07391102.2020.1775704.

15. Park, W.H.; Freeman, R.G.; JAMA, 1926, 87, 556

16. Rambar, A.C.; Am. J. Dis. Child., 1946, 71, 1.

17. Park, W.H.; JAMA, 1932, 99, 1050.

18. Islam, A.; Rafiq, S.; Karim, S.; Laher, I.; Rashid, H. H.; Int. J. Surg., 2020, S1743-9191, 30462.

19. Wiwanitkit, V.; Int. J. Surg., 2020, 80, 26.

20. Cheng, Y.; et al., Eur. J. Clin. Microbiol. Infect. Dis., 2005, 24, 44.

21. Zhou, B.; Zhong, N.; Guan, Y.; N. Engl. J. Med., 2007, 357, 1450.

22. Ko, J. H.; et al., Antivir. Ther., 2018, 23, 617.

23. China puts 245 COVID-19 patients on convalescent plasma therapy. News release. Xinhua. February 28, 2020. Accessed on 10 March 2020.

http://www.xinhuanet.com/english/2020-02/28/c_138828177.htm.

24. Cao, W. C.; Liu, W.; Zhang, P. H.; Zhang, F.; Richardus, J. H.; N. Engl. J. Med., 2007, 357, 1162.

25. I.F.N. et al., Convalescent Plasma Treatment Reduced Mortality in Patients with Severe Pandemic Influenza A (H1N1) 2009 Virus Infection, Clinical Infectious Diseases, 2011, 52, 447.

26. Duan, K.; et al., Effectiveness of convalescent plasma therapy in severe COVID-19 patients, PNAS, 2020, 117, pp.9490-9496.

27. Cheng, Y.; et al., Eur J. Clin Microbiol Infect Dis., 2005, 24, 44. 